\title{
Experimental Study on Solving Ice-blocking by Condensation Heat
}

\section{Recovery}

\author{
Zhi Han, Zhen Wang, Yaying Zhang, Tao Jiang, Hongli Shan
}

\author{
Zhejiang ocean university, No.1, haida south road, DingHai district, ZhouShan city, Zhejiang \\ province, China.
}

a840100300@qq.com, b1204927928@qq.com

\section{Keywords: Ice blockage; Deicing agent; Hot water; Condensation heat}

Abstract: The problem of ice blockage has always been a thorny issue when the fluidized ice equipment is making ice. Based on the origin of ice blockage, we analyze the causes of the problem. And then, we melt the ice with hot water, that is: the heat carried from the compressor (this part of heat can transform $15.0{ }^{\circ} \mathrm{C}$ tap water into $55.0{ }^{\circ} \mathrm{C}$ high temperature hot water) is recycled, guaranteeing the temperature needed to melt ice. Finally, we carry out experiments of melting ice with hot water of different temperatures and find that the effect is better when the temperature is $55.0^{\circ} \mathrm{C}$. Through the implementation of the above technical means, we've solved the ice-blocking when the fluidized ice equipment is making ice.

\section{Introduction}

In recent years, the fishery refrigeration industry in China has shown a great development trend, and cold chain construction has been gradually improved. However, the fishery refrigeration still adopts traditional freezing technology, which seriously affects the quality of aquatic products. The seawater fluidized ice, as a new secondary refrigerant for aquatic products preservation, is featured by rapid cooling speed, advantages like causing no damage to the fish epidermis and mobility[1]. Nonetheless, the popularization of this technology has been influenced by problems like ice blockage when we are making seawater fluidized ice. Therefore, it is of practical significance to solve the ice-blocking in promoting this advanced technology.

There are many reasons for ice blockage, two of which are the main causes: one is that the seawater fluidized ice with high ice contents cannot be easily squeezed out of the ice cylinder, for the sleeve-type heat-exchanger falls flat in the face of shortening the heat-transfer time, reducing fluid resistance and increasing the inlet flow rate. the other is the possibility of agglomeration of ice crystals in the preparation process.

Conventional anti-icing methods are mostly based on melting ice and deicing, such as: thermal ice-melting, over-current ice-melting, heating and oscillation ice-melting, laying of heating conductors, etc. Obviously, these methods are not applicable to the preparation of seawater fluidized ice[2,3]. Our research shows that it is a very effective way to solve the ice-blocking by converting the waste heat from the compressor into the internal energy of tap water via the heat tank[4-6].

\section{Analysis Causes of Ice Blockage}

Water freezing depends on temperature and condensation. In icing problems, the surface can be divided into impinging and obscured areas. The obscured area is a region in which water droplets 
cannot impinge on the surface. Previous studies have shown that there does exist a phenomenon of water droplet collection in the windward zone, and there is a maximum at the stagnation point. As a result of the collection of water droplets, icing occurs on the windward surface where water droplets occasionally impinge on. The crystallization of sea water in an ice cylinder appears to be the process of constant impingement of water on the wall, so ice formation phenomenon is apt to occur.

There are many reasons for ice blockage, including: the seawater fluidized ice with high ice contents cannot be easily squeezed out of the ice cylinder, for the sleeve-type heat-exchanger falls flat in the face of shortening the heat-transfer time, reducing fluid resistance and increasing the inlet flow rate[7-10]. The equipment of fluidized ice heat-exchanger is made of copper material with high surface energy, where the water molecules are easily to adsorb and accumulate, and finally to freeze in the process of making fluidized ice. All these shortages can bring about ice blockage and shutdown of the sleeve-type heat-exchanger, resulting in the reduction of ice-making efficiency. Worse still, the thermal conducting property of copper products is seriously affected, which is detrimental to the stable work of products and equipment.

\section{Study on Solving Ice-blocking by Condensation and Heat Recovery}

In the light of ice-blocking, spraying hot water on the ice blocks is an effective way of melting ice. Given the large discrepancy of temperatures, heat exchange will happen rapidly, and ice will be melted quickly. Inspired by this phenomenon, a method of adding hot water to the fluidized ice equipment is provided to prevent fluidized ice from aggregating into larger particles. It is easy to make, which can be cyclically prepared by sea water. meanwhile, it is resource-saving to directly use hot water from condensation heat recovery tank to melt ice. During the preparation of fluidized ice by seawater, a large amount of heat will be discharged into the environment after the refrigerant passes through the condenser[11-13], which will not only bring about thermal pollution to the outdoor environment but also result in a large amount of heat energy loss and environmental pollution. Hence, a scheme for recovering condensation heat to prepare hot water and store it in a hot water storage tank is put forward. When ice jam is formed, the hot water in the tank can be used to melt the ice in the ice cylinder, which not only reduces energy consumption, but also improves the overall energy utilization of the equipment.

\section{Designed Scheme of Condensation Heat Recovery Unit}

The condensation heat recovery equipment is a device that uses refrigerant to carry heat in a compressor. It mainly includes heat recovery unit and heat storage device. The recovery mechanism of condensation heat is: when the cooling system is running, the compressor starts to work, exerting suction and depressurization effects on the evaporating tube. At this moment, the liquid refrigerant enters the evaporation tube, and then undergoes phase transition to absorb a large amount of heat. Then the vaporized refrigerant is compressed by the compressor to achieve a high temperature and high pressure state. The refrigerant in this state needs to transfer the heat to the environment through the condenser to realize the recycling purpose. The gaseous refrigerant out of the compressor has a very high temperature of up to $96.0^{\circ} \mathrm{C}$, and it is cooled and transformed into liquid when it passes through the waste heat recovery equipment, then it goes back to the expansion valve again, thus circulating[14]. In a word, the condensation heat recovery device is to recover and recycle this part of heat by reasonable technology, so as to ensure the smooth progress of the refrigeration cycle and ultimately achieve the purpose of waste heat recovery.

The condensation heat generated by the refrigerant passing through the compressor is about 1.3 
times the amount of the refrigerating output[8,9]. And the release of condensation heat is relatively concentrated in a certain period of time. The condensation heat can be recovered to prepare $55.0^{\circ} \mathrm{C}$ hot water, which meets the actual requirement for melting ice. However, after several experiments, we have found that the total amount of hot water appears to be $135 \mathrm{~L}$ to completely remove ice under real ice-blocking circumstances. The minimum holding capacity of the hot water storage tank is $200.0 \mathrm{~L}$, which can fully meet the demand of deicing. A hot water storage tank is added to the system, as is shown in Fig 1, to store hot water for deicing or for daily use.

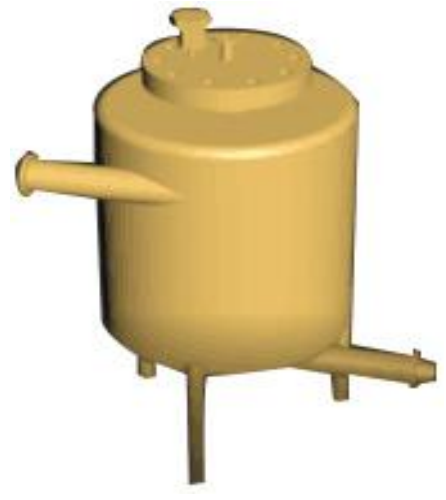

Fig.1 Hot water storage tank

The condensation heat recovery equipment can be divided into direct-type (Fig 2) and indirect-type according to the mode of recovery. In the direct-type, the refrigerant from the compressor goes directly into the heat recovery unit and be stored in the hot water tank. While the indirect-type one refers to the use of high-temperature air discharged from the condenser side to heat the tap-water.

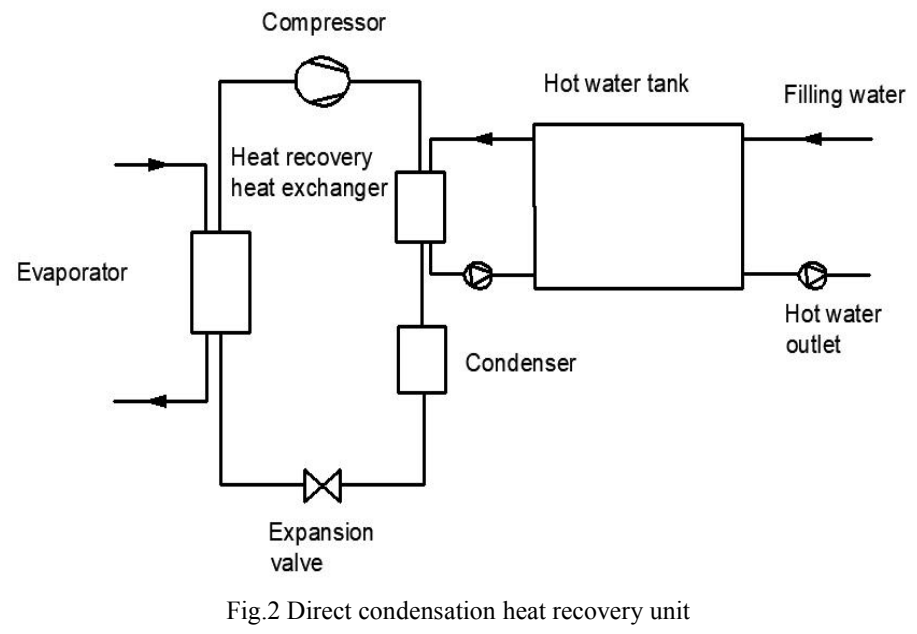

The condensation heat recovery equipment can be divided into single heating type, static heating type (Fig 3) and cyclic heating type (Fig 4). Static heating type is to place the condensing coil in the water tank, directly producing hot water by heating. While the cyclic one comprises the heat-exchanger (plate-type, shell-type, sleeve-type, etc.), the hot water storage tank and water pumps connected in series, indirectly and cyclically heating water. In the static heating type, the heated water in the tank remains stationary, and its thermal conductivity is not high, which will easily bring about hot water stratification. Nevertheless, the cyclic one has better heat exchange effect and the stratification problem is hard to arise. 

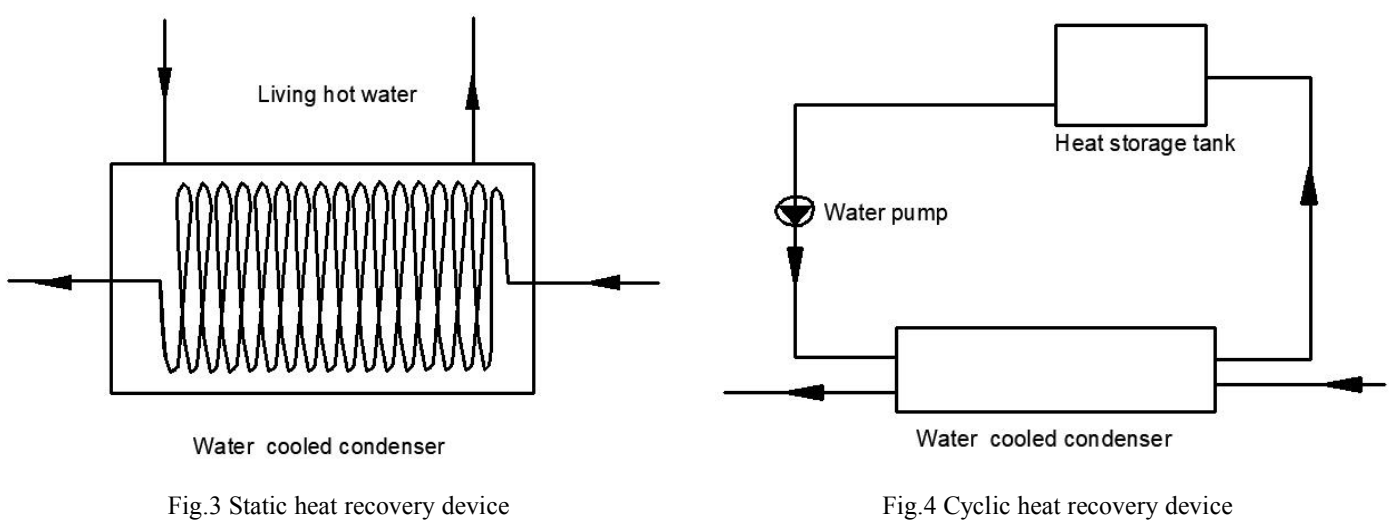

Therefore, our scheme employs the direct-sleeve-type heat-exchanger, together with the cyclic heat recovery device. The role of condensation heat is to lift the temperature of the tap water and to utilize the hot water stored in the tank when ice blockage is formed. In addition, the equipment can reuse the heat discharged, store it in the thermal insulation water tank as domestic water, which plays a role of saving resources and improving the efficiency of energy utilization.

\section{Experimental Verification}

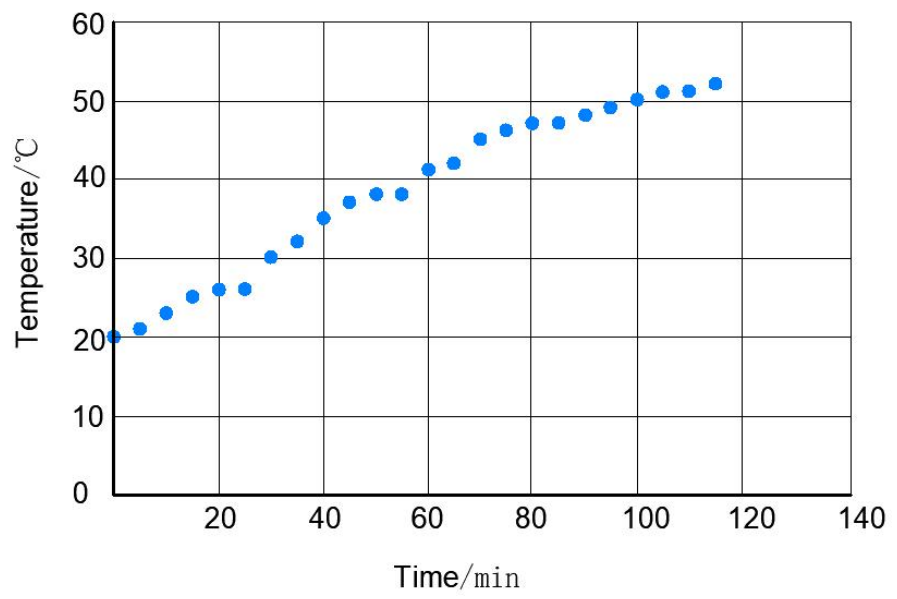

Fig.5 The average water temperature in the tank changes with time

Fig 5 shows how the average water temperature in the tank changes with time. To be specific, the water temperature rise fast at the very beginning, while the speed starts to slow down when the system has been operated for $42.0 \mathrm{~min}$. This is because when the water is heated to $35.0^{\circ} \mathrm{C}$, the water flows to the hot water storage tank through the pipeline, where more condensation heat is taken away. At the same time, due to the increased water temperature, the heat transfer efficiency declines and the amount of heat taken away by the water-cooling condenser decreases gradually. Actually, when the unit has been running for $2.0 \mathrm{~h}$, the $200.0 \mathrm{~L}$ water can be heated from $20.0^{\circ} \mathrm{C}$ to $55.0^{\circ} \mathrm{C}$.

$$
\begin{aligned}
& \mathrm{m}=\rho v=1.0 \times 10^{3} \mathrm{~kg} / \mathrm{m}^{3} \times 200 \times 10^{-3} \mathrm{~m}^{3}=200 \mathrm{~kg} \\
& \mathrm{c}_{\text {水 }}=4.2 \times 10^{3} \mathrm{~J} /\left(\mathrm{kg} \cdot{ }^{\circ} \mathrm{C}\right) \\
& \mathrm{Q}=\mathrm{cm} \Delta \mathrm{t} \\
& Q=4.2 \times 10^{3} \mathrm{~J} /\left(\mathrm{kg} \cdot{ }^{\circ} \mathrm{C}\right) \times 200 \mathrm{~kg} \times 35=2.94 \times 10^{7} J
\end{aligned}
$$

The required energy for heating water from $20.0{ }^{\circ} \mathrm{C}$ to $55.0{ }^{\circ} \mathrm{C}$ is up to $29400.0 \mathrm{~kJ}$ by calculation. That is, the fluidized ice equipment produces a large amount of heat in the process . Therefore, it is necessary to make full use of this part of heat.

Diverse temperatures of hot water will enlarge the temperature differences between the influence and the rate of heat exchange, thus exerting an impact on the deicing effect. Therefore, it is very important to work out the optimum temperature of passed-in hot water. Experiments are 
conducted to test the deicing effect of hot water at the same entry position and moment while under different temperature of $40.0^{\circ} \mathrm{C}, 45.0^{\circ} \mathrm{C}, 50.0^{\circ} \mathrm{C}, 55.0^{\circ} \mathrm{C}$ and $60.0^{\circ} \mathrm{C}$.

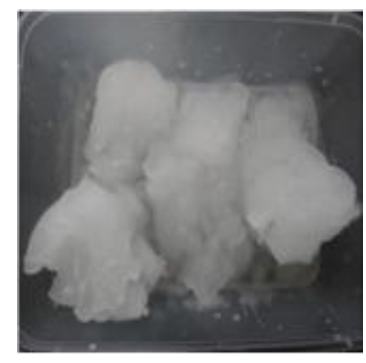

(a) $50^{\circ} \mathrm{C}$ hot water

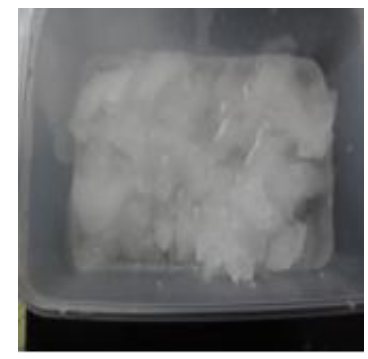

(b) $55^{\circ} \mathrm{C}$ hot water

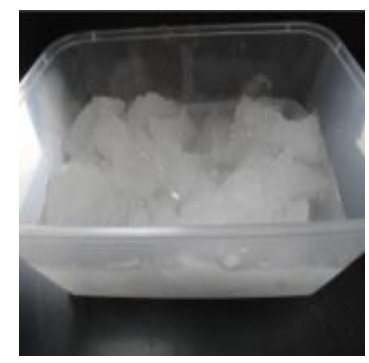

(c) $60^{\circ} \mathrm{C}$ hot water

Fig.6 Ice-melting effects under three different temperatures

The results show that providing the same entrance position and moment, the deicing effect is comparatively remarkable when the temperature of the passed-in hot water is $55.0^{\circ} \mathrm{C}$. The blocked ice of $1.5 \mathrm{~L}$ can be melted in $12 \mathrm{~min}$. Therefore, our scheme employs the direct-sleeve-type heat-exchanger, together with the cyclic heat recovery device, which can fully meet the deicing demand.

\section{Conclusion}

This paper expounds the causes of ice blockage, and puts forward a scheme of using the heat collected by condensation heat recovery equipment during the ice-making process so as to solve the ice-blocking. Finally, we've found that when the temperature of the passed-in hot water is $55.0^{\circ} \mathrm{C}$, the deicing effect is comparatively remarkable, which also enables the recovery of waste heat and energy-saving. In short, the waste heat recovery unit effectively solves the ice-blocking during the ice-making process, guaranteeing continuous ice making of the ice machine in practical application.

\section{Acknowledgements}

This work was supported by The National Sparking Plan Project under the project number 2013GA700254, Zhejiang Provincial Public Projects of China under the project number 2017C31008, Zhoushan Science and Technology Plan Project under the project number $2016 \mathrm{C} 41004$.

\section{References}

[1]Wenji Xu, Jinlong Song, Sun Jing. Analysis of frost effect of anti-icing frost on the surface of aluminum matrix surface [J]. Cryogenic engineering, 2010, 178 (6) : 11-15

[2]Li Hui,Yunhui Zhao, Xiaoyan Yuan. Anti-icing coating: from surface chemistry to functionalized surface[J]. Progress in Chemistry, 2012,24 (11): 2087-2096

[3]Jingyi Du. Design of fan blade anti-icing coatings based on FEVE resin system, zhongyuan kansai coatings chemical co. LTD. Tianjin

[4]Ganglin Liu, Haijun Shen. Study on anti-icing and de-icing technology of aircraft[J]. Jiangsu Airlines, 2003 (4): 18-20

[5]Guangrui Zhang, Xiaodong Yang, Jingfu Jin. Research for Freezing-Adhesive-Coefficients Between Some Engineering Materials and Ice[J]. Journal of Changchun University of Science and Technology, 2004, 3 (27):77-79

[6]M Farzaneh, CC Ryerson. Anti-icing and deicing techniques[J]. Cold Regions Science and Technology, 2011, 65:1-4 
[7]Jie Feng, Jinqiang Lu, Zhaoqian Qin. Research Progress on Anti-icing Performance of Super-hydrophobic Surface[J]. Chinese Journal of Materials Research, 2012, 26 (8): 337-343 [8]Feng Wang, C.R. Li, Y.Z. Lv. Ice accretion on superhydorphobic aluminum surfaces under low-temperature conditions[J]. Cold Regions Science \& Technology, 2010, 62:29-33

[9]R Jafari, R Menini, M Farzaneh. Superhydorphobic and icephobic surfaces prepared by RF-sputtered polytetrafluoroethylene coatings[J]. Applied Surface Science, 2010, 257:1540-1543

[10]L Mishchenko, B Hatton, V Bahadur. Design of ice-free nanostructured surfaces based on repulsion of impacting water droplets[J]. Acs Nano, 2010, 12(4):7699-7707

[11]C Antonini, M Innocenti, T Horn. Understanding the effect of superhydrophobic coatings on energy reduction in anti-icing systems[J]. Cold Regions Science and Technology, 2011, 67(1):58-67

[12]S Farhadi, M Farzaneh, SA Kulinich. Anti-icing performance of superhydrophobic surfaces[J]. Applied Surface Science, 2011, 257(1):6264-6269

[13]Shuqiong Yang, Qiang Xia, Liu Zhu. Research on the icephobic properties of fluoroolymer-based materials[J]. Applied Surface Science, 2011, 257:4956-4962

[14]Hong Wang, GuoGeng He, Qiqi Tian. Effects of nano-fluorocarbon coating on icing[J]. Applied Surface Science, 2012, 258:7219-7224 